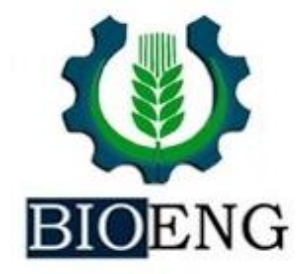

\title{
EFEITO ALELOPÁTICO DE EXTRATO DE CANOLA (Brassica napus) SOBRE A FASE DE GEMINAÇÃO DA CULTURA DA SOJA
}

\author{
J. Borella ${ }^{1 *}$, R. Leschewitz ${ }^{2}$, J. W. Trautenmüller ${ }^{1}$, \\ D. R. O. Silva ${ }^{3}$, D. Schmidt ${ }^{3}$
}

${ }^{1}$ UFPR - Univ Federal do Paraná, Curitiba, PR, Brasil.

${ }^{2}$ Empaer - Empresa Mato-grossense de Pesquisa, Assistência e Extensão Rural, Claudia, MT, Brasil.

${ }^{3}$ UFSM - Univ Federal de Santa Maria, Frederico Westphalen, RS, Brasil.

Article history: Received 17 January 2016; Received in revised form 15 February 2017; Accepted 20 February 2017; Available online 27 March 2017.

\section{RESUMO}

Alelopatia é o fenômeno de interações entre plantas com liberação de substâncias químicas no meio ambiente que provocam efeitos estimulatórios ou inibitórios na germinação, crescimento e desenvolvimento de outras plantas. O presente trabalho teve por objetivo avaliar o efeito alelopático de extrato de canola, na germinação de sementes de cultivares de soja. $\mathrm{O}$ delineamento experimental utilizado foi blocos ao acaso em arranjo fatorial $4 \times 2$, em que o fator A foi composto por 4 cultivares de soja sendo Monasca, Coodetec 219, BMX Potência e BMX Força e o fator B a concentração do extrato sendo $0 \%$ e $10 \%$. O experimento foi conduzido em papel Germitest com 50 sementes para cada cultivar, sem e com extrato aquoso de canola, sendo quatro repetições para cada tratamento, os rolos contendo as sementes foram mantidos em câmara B.O.D. a $25^{\circ} \mathrm{C}$. Foram avaliadas a primeira contagem de germinação, número de sementes germinadas, sementes não germinadas, plântulas anormais, comprimento da parte aérea e radícula, massa seca da parte aérea e da radícula das plântulas. A presença de extrato influenciou o percentual de sementes germinadas, mas ainda a cultivar 'BMX Força', apresentou menor desempenho com e sem a utilização do extrado, em razão das sementes apresentarem menos vigor. A cultivar 'BMX Força' e 'BMX Potência' apresentaram efeitos deletérios quando expostas ao extrato de canola, pelo maior número de sementes anormais. A cultivar BMX Força demostrou maior influência na germinação de sementes com uso do extrato e a Coodetec 219 apresentou bom desempenho como cultivar para ser utilizada em sucessão a cultura da canola.

Palavras-chave: Alelopatia, Brassicaceae, germinação.

\section{ALELOPATIC EFFECT OF CANOLA EXTRACT (Brassica napus) ON THE SOYBEAN CULTURE TWINNING PHASE}

\begin{abstract}
Allelopathy is the phenomenon of interactions between plants with release of chemical substances in the environment that provoke stimulatory or inhibitory effects on the germination, growth and development of other plants. The objective of this work was to evaluate the allelopathic effect of canola extract on the germination of soybean cultivars. The experimental design was a randomized block design in a 4x2 factorial arrangement, in which
\end{abstract}

\footnotetext{
*borella.juli@gmail.com
} 
factor A was composed of four soybean cultivars: Monasca, Coodetec 219, BMX Power and BMX Strength, and factor B the concentration of the extract being $0 \%$ and $10 \%$. The experiment was conducted on Germitest paper with 50 seeds for each cultivar, with and without aqueous extract of canola, four replicates for each treatment, the rolls containing the seeds were kept in chamber B.O.D. At $25^{\circ}$ C. The first germination count, number of germinated seeds, non - germinated seeds, abnormal seedlings, shoot length and radicle, dry mass of shoots and radicle of seedlings were evaluated. The presence of extract influenced the percentage of germinated seeds, but still the cultivar 'BMX Força', presented lower performance with and without the use of the extrado, because the seeds presented less vigor. The cultivar 'BMX Força' and 'BMX Potência' presented deleterious effects when exposed to the canola extract, due to the greater number of abnormal seeds. The cultivar BMX Força demonstrated greater influence on the germination of seeds with the use of the extract and Coodetec 219 showed good performance as cultivar to be used in succession the culture of the canola.

Keywords: allelopathy, Brassicaceae, germination.

\section{INTRODUÇÃO}

A soja destaca-se como uma das principais commodities agrícolas do país, e devido à grande demanda pelos grãos por parte da agroindústria, a oleaginosa é uma das culturas que mais se expande em termos de área cultivada. A soja é um produto destinado à exportação, o qual a torna como um determinante fator para o crescimento do PIB brasileiro (BORTOLINI et al., 2005).

Neste contexto, o Estado do Rio Grande do Sul tem a soja como principal espécie de exploração econômica no período de estação quente do ano. Esta espécie é cultivada tanto em pequenas, médias e grandes estabelecimentos agrícolas e faz parte de diversos sistemas de produção da região (MAPA, 2015).

A canola pertence à família Brassicaceae, gênero Brassica, originária de uma seleção de cultivares de colza, possuindo em seus grãos teores de óleo que variam entre 40 e $46 \%$, apresentando baixo teor de gorduras saturadas. O óleo é utilizado na alimentação humana de forma in natura, para realização de frituras em geral e para a fabricação de margarinas (ROSA, 2009). No entanto, com a crescente implantação da canola no inverno, vários produtores no estado do Rio Grande do Sul têm observado que a cultura apresenta inconveniências quando antecessora à soja devido, possivelmente, ao efeito alelopático, dos quais necessitam ser investigados.

O fenômeno denominado alelopatia pode causar efeito direto ou indireto, benéfico ou prejudicial, de uma planta sobre a outra, mediante produção de compostos químicos que são liberados no meio ambiente (BRASS, 2009). O modo de ação indireto dos aleloquímicos ocorre quando o composto produzido altera primeiramente as propriedades químicas do solo, já o efeito direto ocorre quando a substância química interfere no metabolismo vegetal. Os efeitos visíveis dos aleloquímicos são manifestações secundárias, que são observadas após alterações a nível molecular e celular (FERREIRA \& ÁQUILA, 2000).

Atualmente, vários estudos têm sido realizados com alelopatia, podendo citar Wandscheer et al. (2011), realizaram estudo com folhas e pseudofrutos de Hovenia dulcis Thunb, sobre a germinação de alface, Oliveira et al. (2012), utilizando extrato de partes de juazeiro, Gomaa et al. (2014), realizaram estudo com Sonchus oleraceus, Borella et al. (2011) trabalharam com extrato de Solanum americanum, Silva et al. (2012), estudaram o efeito de extratos de Pteridium aquilinum sobre germinação e desenvolvimento inicial de rúcula. 
O conhecimento de resultados experimentais mais efetivos dos possíveis efeitos da canola sobre a cultura da soja, não tem sido encontrado na literatura de forma mais conclusiva. Além disto, existe um grande interesse pelos agricultores e técnicos da região em conhecer os prováveis efeitos desta sucessão, principalmente no sentido de estabelecer qual o momento adequado entre a semeadura da soja após colheita da canola, determinando uma margem de segurança que não inviabilize o emprego destas duas espécies no sistema de sucessão de culturas.

\section{MATERIAL E MÉTODO}

O experimento foi conduzido no Laboratório de Fitopatologia da Universidade Federal de Santa Maria campus Frederico Westphalen - Rio Grande do Sul, Brasil. O experimento foi realizado em câmara de germinação do tipo B.O.D., sob condições controladas de fotoperíodo $(12 \mathrm{~h})$ e temperatura $\left(25^{\circ} \mathrm{C}\right)$.

$\mathrm{O}$ experimento foi em blocos ao acaso e o esquema utilizado foi bifatorial (4x2), sendo fator A por cultivares: 'MONASCA', 'COODETEC 219', 'BMX Potência' e 'BMX Força'; e fator B extrato de canola nas concentrações 0 e $10 \%$, com quatro repetições para cada tratamento.

O extrato aquoso foi obtido das folhas, caule e raízes de canola (Brassica napus L), sendo a planta inteira, com 130 dias de idade, no estádio de florescimento, cultivadas em condições de campo. Após obtenção do material a campo, o mesmo foi conduzido até o laboratório, onde se procedeu à lavagem em água corrente. Para a preparação do extrato, a massa fresca foi triturada em liquidificador com água destilada em uma proporção de $10 \mathrm{~g}$ de massa para $100 \mathrm{~mL}$ de água $(10 \%)(\mathrm{m} / \mathrm{v})$. Para o controle sem o extrato de canola utilizou-se apenas água destilada.

Os lotes de sementes de cada cultivar de soja utilizados no presente estudo foram obtidos da safra 2013/2014, junto à Agropecuária Giruá, localizada no município de Giruá, Rio Grande do Sul,
Destaca-se, a obtenção de informações referentes ao efeito alelopático no processo de germinação e a identificação de cultivares com a capacidade de superar este estresse químico, permite identificar maneiras de minimizar o efeito da desuniformidade na germinação, buscando a obtenção de um adequado estande de plantas como recomendado para a cultura. $\mathrm{O}$ trabalho teve por objetivo avaliar o efeito alelopático de extrato de canola, na germinação de sementes de cultivares de soja.

Brasil. Foram confeccionados rolos de papel Germitest com 50 sementes, utilizouse duas folhas sob a face inferior das sementes, e uma sobre a face superior. $\mathrm{O}$ papel foi umedecido com água destilada (controle) e com o extrato aquoso de canola com volume correspondente a 2,5 vezes o peso do papel.

As variáveis avaliadas foram primeira contagem de germinação (PCG), número de semente germinadas (G) sementes não germinadas (NG), plântulas anormais (PA), comprimento de parte aérea (CPA), comprimento de radícula (CRD), massa seca de parte aérea (MSPA) e massa seca de radícula (MSRD) em cultivares de soja.

A primeira contagem de germinação foi realizada quatro dias após o início do experimento. $\mathrm{O}$ número de sementes germinadas, não germinadas e sementes anormais foram realizados aos oito dias após o início do experimento (BRASIL, 2009).

Para as variáveis CPA, CRD, MSPA e MSRD foram confeccionados rolos com papel Germitest por meio do teste de germinação. Constituíram-se de 20 sementes para cada repetição, dispostas com o hilo para baixo. Ao final de oito dias do início do experimento a CPA e CRD foram mensurados com auxílio de régua milimetrada. Com estilete separou-se a parte aérea e raiz, em seguida, as amostras 
foram acondicionadas em estufa com ventilação forçada de ar mantida a temperatura de $65{ }^{\circ} \mathrm{C}$ até obtenção de massa constante (HOSHINO, et al 2016). Após este período foram obtidas as biomassas secas em balança analítica, com precisão $0,001 \mathrm{~g}$.

\section{RESULTADOS E DISCUSSÃO}

Não houve efeito de interação entre os fatores estudados. A análise complementar pelo teste Tukey mostrou diferença significativa entre cultivares, para todas as variáveis, e em relação, com e sem uso de extrato, as variáveis primeira contagem e sementes germinadas, não apresentaram diferença estatística. Apenas a porcentagem de plântulas anormais, $o$ número de sementes não germinadas, comprimento de parte aérea, comprimento de radícula, massa seca de parte aérea e massa seca de radícula foram significativas.
Os dados foram submetidos à análise de variância pelo teste $\mathrm{F}$ a $5 \%$ de probabilidade de erro, se significativas, comparados pelo teste de Tukey a 5\% de probabilidade por meio do software SAS Learning Edition 8.0 (2003).

Tabela 1. Análise dos efeitos alelopáticos de extrato aquoso de canola e seus efeitos sobre as variáveis primeira contagem de germinação (PCG), número de sementes germinadas $(\mathrm{G})$, plântulas anormais (PA) e sementes não germinadas (NG) em cultivares de soja. Frederico Westphalen - RS, Brasil, 2014.

\begin{tabular}{|c|c|c|c|c|c|c|c|c|}
\hline \multirow{2}{*}{ Cultivar } & \multicolumn{2}{|c|}{ PCG (\%) } & \multicolumn{2}{|c|}{$\mathrm{G}(\%)$} & \multicolumn{2}{|c|}{$\mathrm{PA}(\%)$} & \multicolumn{2}{|c|}{$\mathrm{NG}(\%)$} \\
\hline & $0 \%$ & $10 \%$ & $0 \%$ & $10 \%$ & $0 \%$ & $10 \%$ & $0 \%$ & $10 \%$ \\
\hline Monasca & ${ }^{\mathrm{ns}} 94,0 \mathrm{a}$ & $96,5 \mathrm{a}$ & ${ }^{\mathrm{ns}} 88,5 \mathrm{a}$ & $88,5 \mathrm{ab}$ & ${ }^{\mathrm{ns}} 5,3 \mathrm{a}$ & $8,3 \mathrm{~b}$ & $* 6,3 \mathrm{~b}$ & $3,3 \mathrm{~b}$ \\
\hline Coodetec 219 & ${ }^{\mathrm{ns}} 98,2 \mathrm{a}$ & $98,0 \mathrm{a}$ & ${ }^{\mathrm{ns}} 93,5 \mathrm{a}$ & $92,3 \mathrm{a}$ & ${ }^{\mathrm{ns}} 4,0 \mathrm{a}$ & $6,0 \mathrm{~b}$ & ${ }^{\mathrm{ns}} 2,3 \mathrm{~b}$ & $1,8 \mathrm{~b}$ \\
\hline $\begin{array}{l}\text { BMX } \\
\text { Potencia }\end{array}$ & ${ }^{\mathrm{ns}} 96,0 \mathrm{a}$ & $94,0 \mathrm{a}$ & ${ }^{\mathrm{ns}} 89,3 \mathrm{a}$ & $86,0 \mathrm{~b}$ & $* 5,8 \mathrm{a}$ & $10,3 a b$ & ${ }^{\mathrm{ns}} 5,0 \mathrm{~b}$ & $3,8 \mathrm{~b}$ \\
\hline BMX Força & ${ }^{\mathrm{ns}} 85,3 \mathrm{~b}$ & $81,25 b$ & ${ }^{\mathrm{ns}} 77,3 \mathrm{~b}$ & $73,3 \mathrm{c}$ & $* 7,8 \mathrm{a}$ & $14,0 \mathrm{a}$ & ${ }^{\mathrm{ns}} 15,0 \mathrm{a}$ & $12,8 \mathrm{a}$ \\
\hline Média & 81,38 & 80,44 & 87,13 & 85,00 & 5,69 & 9,63 & 7,13 & 5,38 \\
\hline $\mathrm{CV}(\%)$ & \multicolumn{2}{|c|}{4.09} & \multicolumn{2}{|c|}{5,15} & \multicolumn{2}{|c|}{40,22} & \multicolumn{2}{|c|}{48.99} \\
\hline
\end{tabular}

* $\mathrm{e}^{\mathrm{ns}}$ indicam significativo e não significativo, respectivamente, na comparação na linha e médias seguidas de mesma letra minúscula na coluna não diferem entre si, ambos pelo teste de Tukey, ao nível de 5\% de probabilidade.

A cultivar 'Coodetec 219' obteve a maior porcentagem de germinação dentre as cultivares analisadas, e a cultivar 'BMX Força' como sendo a que apresentou menor porcentagem de germinação, sem o uso de extrato. Com o uso de extrato algumas cultivares tenderam a diminuir o percentual de sementes germinadas, mas ainda a cultivar 'BMX Força', apresentou menor desempenho com e sem a utilização do extrato, esse efeito causado na germinação das sementes pode estar relacionado ao efeito tóxico causado pelo compostos presentes no extrato de canola, interferindo nas vias de hidrolise de reservas.

A canola apresenta efeitos nocivos nas culturas, incluindo a germinação reduzida das sementes e a emergência de culturas subsequentes de grãos quando 
cultivadas em rotação (HADDADCHI et al., 2009).

Os compostos das substâncias fenólicas na canola como o ácido sinápico e a sinapina (ZUKALOVA, 1999), podem promover a diminuição da germinação das sementes, captação iónica, expansão foliar, conteúdo de clorofila, fotossíntese e transporte de elétrons (COLPAS et al., 2003; LEU et al., 2002).

A utilização de altas concentrações de extratos pode estar relacionado a maior concentração de substâncias tóxicas (SILVA et al., 2016). A diminuição do número de sementes germinadas está relacionado a interferência causada pelos compostos sobre as vias de hidrólise de reserva (MUNIZ et al., 2007).

Em estudo realizado Rizzardi et al. (2008) verificaram que o aumento do extrato de canola de 0 a $100 \%$, reduz a germinação de aquênios de picão-preto em $80 \%$. Isso ocorre, segundo Norsworthy (2003), devido a produção de glucosinolatos, aleloquímicos que podem ser os responsáveis pelos efeitos inibitórios no crescimento de plantas.

Em trabalho realizado por Haddadchi et al. (2009) ao utilizarem extrato de canola nas concentrações $10 \%$, $20 \%$ e $30 \%$ das partes seca de canola mostraram que com o aumento da dose maior a influência sobre o desenvolvimento de soja.

A cultivar 'BMX Força' e 'BMX Potência' apresentaram efeitos deletérios quando expostas ao extrato de canola, uma vez que ambas aumentaram o percentual de plântulas anormais. Embora as cultivares 'Monasca' e 'Coodetec 219' não terem apresentado significância em relação ao uso de extrato, as mesmas também tenderam a aumentar o número de sementes anormais (Tabela 1). $\mathrm{O}$ estresse causado pelo efeito alelopático do extrato de canola pode ter provocado distúrbios na germinação, o que veio a contribuir no aumento significativo de plântulas anormais.

Estudos têm demonstrado a ação tóxica de extratos sobre a massa seca de plântulas (TUR et al., 2012). Carmo et al. (2007), ao realizarem estudo com extratos de folhas e de cascas de tronco de Ocotea odorifera, verificaram a redução da massa seca total de plântulas de Sorghum bicolor, indiferentemente da concentração.

A cultivar 'BMX Força' apresentou o maior número de sementes não germinadas, tanto quando exposta ao extrato quanto em sua ausência. A cultivar 'Monasca' apresentou aumento na germinação quando tratadas com o extrato de canola.

As cultivares 'Coodetec 219' e BMX Potência' diminuíram o comprimento da parte aérea em meio contendo o extrato de canola, sendo que na sua ausência a cultivar 'BMX Força' obteve o menor comprimento de parte aérea (Tabela 2 ). 
Tabela 2. Análise dos efeitos alelopáticos de extrato aquoso de canola e seus efeitos sobre as variáveis, comprimento da parte aérea (CPA), comprimento da radícula (CR), massa seca de parte aérea (MSPA) e massa seca de radícula (MSRD) em cultivares de soja. Frederico Westphalen - RS, Brasil, 2014.

\begin{tabular}{|c|c|c|c|c|c|c|c|c|}
\hline \multirow{2}{*}{ Cultivar } & \multicolumn{2}{|c|}{$\mathrm{CPA}(\mathrm{cm})$} & \multicolumn{2}{|c|}{$\mathrm{CR}(\mathrm{cm})$} & \multicolumn{2}{|c|}{ MSPA (g) } & \multicolumn{2}{|c|}{ MSRD (g) } \\
\hline & $0 \%$ & $10 \%$ & $0 \%$ & $10 \%$ & $0 \%$ & $10 \%$ & $0 \%$ & $10 \%$ \\
\hline Monasca & ${ }^{\mathrm{ns}} 6.59 \mathrm{a}$ & $6.53 \mathrm{a}$ & ${ }^{\mathrm{ns}} 6.14 \mathrm{~b}$ & $6.99 \mathrm{~b}$ & $* 1.415 \mathrm{a}$ & $1.023 \mathrm{~b}$ & ${ }^{\mathrm{ns}} 0.113 \mathrm{~b}$ & $0.088 \mathrm{~b}$ \\
\hline Coodetec 219 & $* 9.21 \mathrm{a}$ & $6.65 \mathrm{a}$ & $* 7.13 \mathrm{~b}$ & $11.43 \mathrm{a}$ & $* 1.287 \mathrm{a}$ & $1.061 \mathrm{~b}$ & $* 0.098 \mathrm{~b}$ & $0.165 \mathrm{a}$ \\
\hline $\begin{array}{c}\text { BMX } \\
\text { Potencia }\end{array}$ & * & 6.5 & b & 7.1 & b & $4 \mathrm{a}$ & ${ }^{\mathrm{ns}} 0.075 \mathrm{~b}$ & $0.077 \mathrm{~b}$ \\
\hline BMX Força & ${ }^{\mathrm{ns}} 6.82 \mathrm{~b}$ & $6.26 \mathrm{a}$ & $* 10.32 \mathrm{a}$ & $5.83 \mathrm{~b}$ & $* 0.999 \mathrm{~b}$ & $1.358 \mathrm{a}$ & $* 0.232 \mathrm{a}$ & $0.081 \mathrm{~b}$ \\
\hline Média & 7.74 & 6.51 & 7.52 & 7.85 & 1.17 & 1.13 & 0.130 & 0.103 \\
\hline $\mathrm{CV}(\%)$ & \multicolumn{2}{|c|}{14.26} & \multicolumn{2}{|c|}{30.46} & \multicolumn{2}{|c|}{17.50} & \multicolumn{2}{|c|}{42.33} \\
\hline
\end{tabular}

* $\mathrm{e}^{\mathrm{ns}}$ indicam significativo e não significativo, respectivamente, na comparação na linha e médias seguidas de mesma letra minúscula na coluna não diferem entre si, ambos pelo teste de Tukey, ao nível de 5\% de probabilidade.

Para o parâmetro de comprimento de radícula percebe-se que a cultivar 'BMX Força' apresentou o maior comprimento dentre as cultivares estudados sem a presença do extrato de canola. Contudo, esta variável foi reduzida quando submetida a presença de extrato. A cultivar 'BMX Potência' a presença de extrato a $10 \%$ diminuiu o comprimento de radícula, observa que ocorreu aumento do comprimento da radícula apenas para a cultivar 'Coodetec 219'.

Esses resultados de estímulo no comprimento da radícula provavelmente devem-se à presença de alguns aleloquímicos com ação estimulatória, sendo caracterizado como efeito alelopático (CARVALHO et al., 2002).

Mesmo sabendo que um dos sintomas citados, é a inibição da germinação, sabe-se que em determinadas concentrações o efeito pode ser positivo, sendo o caso da cultura da soja, por apresentar grande variabilidade genética, justifica $\mathrm{o}$ fato de estar tendo efeito benéfico com o uso do extrato, para o comprimento de radícula (EBERLEIN, 1998).

Devemos levar em consideração os fatores inerentes a cada cultivar, pois a cultivar 'BMX Força' se mostrou mais sensível a exposição ao extrato, diminuindo o comprimento de radícula. As raízes são mais sensíveis as substâncias que estão presentes nos extratos, em comparação com as demais partes da planta (CHON et al., 2000), por estarem em contato direto e prolongado com o aleloquímico em relação às demais estruturas das plântulas e/ou a um reflexo da fisiologia distinta entre as estruturas (AQUILA et al., 2000).

A massa seca de parte aérea sofreu influência para todas as cultivares quando expostas ao extrato. Houve interferência negativa para as cultivares 'Coodetec 219' e 'Monasca', com diminuição de massa seca.

Para massa seca de radícula, a cultivar 'Coodetec 219' apresentou o maior valor de massa seca de radícula com a utilização do extrato e a cultivar 'BMX Força' com maior massa de radícula sem o uso de extrato. Para a comparação com extrato e sem extrato, a massa seca de radícula tendeu a ser menor para 'BMX Força' quando se utilizou concentração de canola, com exceção da cultivar 'Coodetec 219', que tendeu a aumentar a massa seca. $\mathrm{O}$ fato da cultivar 'Coodetec' ter apresentado maior comprimento de radícula e não ter sofrido influencia na germinação quando submetida ao extrato de canola, faz com que a mesma seja uma cultivar para se utilizar em sucessão a canola. 


\section{CONCLUSÃO}

Constatou-se a existência de efeito alelopático da canola no potencial fisiológico das cultivares Coodetec 219, BMX Potência, BMX Força e Monasca, seja na germinação de sementes ou no desenvolvimento das plântulas. Cabe ressaltar que a cultivar BMX Força

\section{REFERÊNCIAS BIBLIOGRÁFICAS}

AQUILA, M. E. A. Efeito alelopático de Ilex paraguariensis A. St.-Hil. na germinação e crescimento inicial de Lactuca sativa L. Iheringia. Série botânica, v.53 (23): 51-66, 2000.

BRASIL - Ministério da Agricultura Pecuária e Abastecimento. Regras para análise de sementes. Secretaria de Defesa Agropecuária. Brasília, DF: Mapa/ACS. 395p. 2009.

BRASS, F. E. B. Análise de atividade alelopática de extrato aquoso de falsa murta sobre a germinação de picão-preto e caruru. Enciclopédia Biosfera, v.5 (8): 119, 2009.

BORELLA, J.; WANDSCHEER, A. C. D.; PASTORINI, L. H. Potencial alelopático de extratos aquosos de frutos de Solanum americanum Mill sobre as sementes de rabanete. Revista Brasileira de Ciências Agrárias, v.6 (2): 309-313, 2011.

BORTOLINI, P. C. et al. Produção de forragem e de grãos de aveia branca sob pastejo. Revista Brasileira de Zootecnia, v. 34 (6): 2192-2199, 2005.

CARMO, F.M.S., BORGES, E.E.L. \& TAKAKI, M. Alelopatia de extratos aquosos de canela-sassafrás (Ocotea odorifera (Vell.) Rohwer. Acta Botânica Brasílica 21(1):697-705, 2007.

CARVAlHO, G. J.; FONTANÉTti, A. A.; CANÇADO, C. T. Potencial alelopático do feijão de porco (Canavalia ensiformes) e da mucuna preta (Stilozobium aterrimum) no controle da demostrou maior influência na germinação de sementes com uso do extrato, já a cultivar Coodetec 219 apresentou pouca influência com a utilização do extrato, sendo uma cultivar promissora para se utilizar em sucessão a cultura da canola.

tiririca (Cyperus rotundus). Ciência e Agrotecnologia, v.26 (3): 647-651, 2002.

CHON, S. U.; COUTTS, J. H.; NELSON, C. J. Effects of light, growth media, and seedling orientation on bioassays of alfalfa autotoxicity. Agronomy Journal, v.92 (4): 715-720, 2000.

COLPAS, F.T., ONO, E.O., RODRIGUES, J.D., PASSOS, J.R. Effects of some phenolic compounds on soybean seed germination and on seed-borne fungi. Brazilian Archives of Biology and Technology. v.46 (2):155-161, 2003.

EBERLEIN, C. V.; MORRA, M. J.; GUTTIERI, M. J.; BROWN, P. D.; BROWN, J. Glucosinolate production by five field-crown Brassica napus cultivars used as green manures. Weed Technology, v.12 (4): 712-718, 1998.

FERREIRA, A. G. \& ÁQUILA, M. E.A. Alelopatia: uma área emergente da ecofisiologia. Revista Brasileira de Fisiologia Vegetal. v.12 (edição especial):175-204, 2000.

GOMAA, N. H.; HASSAN, M. O.; FAHMY, G. M.; GONZÁLES, L.; HAMMOUDA, O.; ATTEYA, A. M. Allelopathic effects of Sonchus oleraceus L. on the germination and seedling growth of crop and weed species. Acta Botanica Brasilica, v.28 (3): 408-416, 2014.

HADDADCHI, G.R.; GERIVANI, $Z$. Effects of Phenolic Extracts of Canola (Brassica napuse L.)on Germination and Physiological Responses of Soybean (Glycin $\max$ L.) Seedlings. International 
Journal of Plant Production, V.3(1): 63-74, 2009.

HOSHINO, R.T., ALVES, G.A.C., MELO, T.R., BARZAN, R.R., FREGONEZI, G.A.F., FARIA, R.T. Adubação mineral e orgânica no desenvolvimento de orquídea Cattlianthe 'Chocolate drop'. Horticultura brasileira, v34 (4), 2016.

LEU, E., KRIEGER-LISZKAY, A., GOUSSIAS, C., GROSS, E.M. Polyphenolic allelochemicals from the aquatic angiosperm Myrophyllum spicatum inhibit photo system II. Plant Physiol. 130: 2011-2018, 2002.

MAPA. 2015. Ministério da Agricultura Pecuária e Abastecimento. In: Departamento de Economia Rural. Disponível em: http://www.agricultura.gov.br/>. Acesso em: 30.abril. 2015

MUNIZ, F.R., CARDOSO, M.G., VON PINHO, E.V.R. \& VILLELA, M. Qualidade Fisiológica de sementes de milho, feijão, soja e alface na presença de extrato de tiririca. Revista Brasileira de Sementes 29(2):195-204, 2007.

NORSWORTHY, J. K. Allelopathic potencial of wild radish (Raphanus raphanistrum). Weed Technology, v. 17, n. 2, p. 307-313, 2003.

OLIVEIRA, A. K.; COELHO, M. F. B.; MAIA, S. S. S.; DIÓGENES, F. E. P.; FILHO, M. S. Atividade alelopática de extratos de diferentes partes de juazeiro (Ziziphus joazeiro Mart. - Rhamnaceae). Acta Botanica Brasilica v.26 (3): 685690, 2012.

RIZZARDI, A.; RIZZARDI, M.A.; LAMB, T.D.; JOHANN, L.B. Potencial alelopático de extratos aquosos de genótipos de canola sobre Bidens pilosa. Planta daninha vol.26 (4), 2008.

ROSA, L. C. R.; GARRAFA, M. Análise dos modos de falha e efeitos na otimização dos fatores de produção no cultivo agrícola: subprocesso colheita da canola. Gestão e Produção, v.16 (1): 63-73, 2009.
SAS LEARNING EDITION. Getting started with the SAS learning edition. Cary, 2003. 200 p.

SILVA, J. E. N.; SILVA, R. G. P. O.; FILHO, A. L. M.; SILVA, C. F. C.; SILVA, M. F. Efeito alelopático de Pteridium aquilinum (L.) kuhn. Sobre germinação e desenvolvimento inicial de rúcula (Eruca sativa L.). Enciclopédia biosfera, v.8 (14):4- 3, 2012.

SILVA, T.A.; DELIAS, D.; PEDÓ, T.; ABREU, E.S.; VILLELA, F.A.; AUMONDE, T.Z. Fitotoxicidade do extrato de Conyza bonariensis (L.) Cronquist no desempenho fisiológico de sementes e plântulas de alface. Iheringia, Série Botânica, 71(3):213-221, 31 de dezembro de 2016.

TUR, C.M., MARTINAZZO, E.G., AUMONDE, T.Z. \& VILLELA, F.A. Atividade alelopática de extratos aquosos de folhas de rabo-debugio sobre a germinação e o crescimento inicial de plântulas de alface. Revista brasileira de Biociências 10(4):521-525, 2012.

ZUCALOVA, H., VA-AK, J. Natural antioxidants in winter rape (Brassica napus L.). Proceeding of 10th international rapeseed congress, Canberra, Australia. The Regional Institute: online community publishing, 1999.

WANDSCHEER, A.C.D., BORELLA, J., BONATTI, L.C., PASTORINI, L.H. Atividade alelopática de folhas e pseudofrutos de Hovenia dulcis Thunb. (Rhamnaceae) sobre a germinação de Lactuca sativa L. (Asteraceae). Acta Botânica Brasílica. v.25 (1), 2011. 